\title{
Comparação do desempenho do teste de captura híbrida II para HPV, citologia em meio líquido e citologia convencional na detecção precoce do câncer do colo do útero e de suas lesões precursoras no Rio de Janeiro, Brasil
}

Comparison of hybrid capture II, liquid based cytology and Pap test for the early detection of the cervical cancer in Rio de Janeiro, Brasil

\author{
Vania Reis Girianelli, Luiz Claudio Santos Thuler, Moyses Szklo, Alexandre Donato, Lucília Maria Gama Zardo, José Azevedo Lozana, Olimpio \\ Ferreira de Almeida Neto, Aurenice Cristina Leda de Carvalho, Jorge Henrique de Matos e Valeska Figueiredo
}

O câncer do colo do útero permanece como uma importante causa de morbidade e mortalidade no Brasil. Embora o exame citopatológico seja o método mais difundido mundialmente para seu rastreamento e de suas lesões precursoras, sua vulnerabilidade a erros de coleta, de preparação da lâmina e a subjetividade na interpretação dos resultados podem comprometer sua sensibilidade e especificidade. $\mathrm{N}$ ovas técnicas vêm sendo desenvolvidas com o objetivo de melhorar a acurácia do exame citopatológico, destacando-se entre elas a citologia em meio líquido. Por outro lado, há evidências epidemiológicas e moleculares do papel do papilomavírus humano (H PV) como fator causal da neoplasia cervical, sendo possível sua detecção por meio de exames de captura híbrida.

Diante disso, o Instituto N acional de Câncer (INCA), responsável por planejar, coordenar e implementar estratégias visando ao controle de câncer no Brasil, desenvolveu este estudo com o objetivo de comparar o desempenho do teste de captura híbrida II para o DN A do H PV, colhido por profissional de saúde (CH PS) e pela própria paciente (CH PP), com a citologia em meio líquido DNACITOLIQ (CL) e a citologia convencional (CC), na detecção precoce do câncer do colo do útero ou suas lesões precursoras. A seguir, são apresentados, de forma sintética, a metodologia e resultados parciais do estudo.

Foram avaliadas 1777 mulheres, de 25 a 59 anos de idade, assistidas pelos Programas de Saúde da Família (PSF) ou de Agentes Comunitários de Saúde (PACS), nos municípios de $\mathrm{D}$ uque de $\mathrm{C}$ axias e $\mathrm{N}$ ova I guaçu, localizados na região metropolitana do Rio de Janeiro, no período compreendido entre dezembro de 2001 e julho de 2002. Em uma mesma consulta, foram colhidas amostras para realização de CC, CL, CH PS e CH PP. Colposcopia foi realizada em todas as mulheres que apresentaram pelo menos um exame alterado e em uma amostra sistemática daquelas com todos os resultados negativos. 0 exame anatomopatológico foi definido como padrão ouro para todos os casos.

A concordância entre os exames foi analisada por meio do coeficiente kappa. Foram estimados a sensibilidade (SEN), a especificidade (ESP) e os valores preditivos positivo (VPP) e negativo (VPN), com os respectivos intervalos com 95\% de confiança (IC 95\%) para cada estratégia.

A média de idade das mulheres foi de 39 anos, 70\% tinham menos de 7 anos de escolaridade, 87\% não usavam preservativo nas relações sexuais e $13,5 \%$ nunca tinham realizado exame preventivo de Papanicolaou.

Foram observadas alterações em $9,6 \%$ das CC e $16,2 \%$ das CL. HPV com alto risco oncogênico foi detectado em $11,4 \%$ das CHPS e $14,0 \%$ das CH PP. Foram encaminhadas para colposcopia 655 mulheres, sendo detectadas no exame anatomopatológico 67

Trabalho realizado no Instituto N acional de Câncer. Endereço para correspondência: L.C.S.T. Rua dos Inválidos, 212/40 andar - CEP: 20.231-020 - Centro - Rio de Janeiro - RJ, Brasil. 
$(29,5 \%)$ lesões de caráter benigno, 74 (32,6 \%) casos sugestivos de HPV, 51 (22,5\%) casos de NIC I, 15 $(6,6 \%)$ casos de NIC II, 18 (7,9\%) casos de NIC III, $1(0,4 \%)$ adenocarcinoma "in situ" e $1(0,4 \%)$ adenocarcinoma invasor.

A coeficiente kappa para a medida da concordância entre a CC e a CL foi de 0,26 e entre a CHPS e a CHPP foi de 0,51. N este estudo, para se diagnosticar um caso de lesão precursora ou câncer do colo do útero foi necessário realizar 56 CH PS, 66 CH PP, 71 CC e 81 CL.

Os valores estimados para SEM, ESP, VPP e VPN são apresentados na tabela 1.

Conclui-se que a concordância entre a $\mathrm{CC}$ e a $\mathrm{CL}$ foi fraca e entre a CHPS e a CHPP foi razoável. A CHPS apresentou sensibilidade superior aos demais exames, enquanto a maior especificidade foi observada com o emprego da CC, embora muito próxima da observada com o uso da CH PS. O s VPP mais elevados foram obtidos com o uso da CHPS e CC, enquanto os VPN, para as quatro estratégias, apresentaram valores semelhantes. N este estudo, diferente do que ocorre no atendimento de rotina à mulher, $\mathrm{a} C \mathrm{C}$ foi colhida após a CC, o que pode influenciar o percentual de exames insatisfatórios e o desempenho do teste pela ocorrência de esfregaços hemorrágicos.

O s resultados apresentados não permitem concluir sobre a melhor estratégia para rastreamento populacional do câncer do colo do útero e de suas lesões precursoras, o que será possível por meio de uma análise custoefetividade em curso.

Fontes de financiamento: DIGENE do Brasil LTDA, Instituto N acional de Câncer (IN CA) e Fundação Ary Frauzino para Pesquisa e Controle do Câncer (FAF).

Tabela 1 - Sensibilidade, especificidade, valor preditivo positivo (VPP) e valor preditivo negativo (VPN) dos exames sob estudo, tendo como padrão ouro o exame anatomopatológico.

\begin{tabular}{c|c|c|c|c}
\hline ESTRATÉGIA & $\begin{array}{c}\text { Sensibilidade } \\
\text { (IC 95\%) }\end{array}$ & $\begin{array}{c}\text { Especificidade } \\
\text { (IC 95\%) }\end{array}$ & $\begin{array}{c}\text { VPP } \\
\text { (IC 95\%) }\end{array}$ & $\begin{array}{c}\text { VPN } \\
\text { (IC 95\%) }\end{array}$ \\
\hline Citologia convencional (CC) & $71,4(53,4-84,8)$ & $91,6(90,2-92,8)$ & $14,6(9,9-21,0)$ & $99,4(98,8-99,7)$ \\
\hline Citologia em meio líquido (CL) & $66,7(48,1-81,4)$ & $84,8(83,0-86,5)$ & $7,9(5,1-11,9)$ & $99,2(98,6-99,6)$ \\
\hline $\begin{array}{c}\text { DNA do HPV colhido por } \\
\text { profissional de saúde (CHPS) }\end{array}$ & $91,4(75,8-97,8)$ & $90,2(88,7-91,5)$ & $15,8(11,2-21,7)$ & $99,8(99,4-100,0)$ \\
\hline $\begin{array}{c}\text { DNA do HPV colhido pela } \\
\text { paciente (CHPP) }\end{array}$ & $77,1(59,4-89,0)$ & $87,3(85,6-88,8)$ & $10,9(7,4-15,6)$ & $99,5(98,9-99,8)$ \\
\hline
\end{tabular}

Abreviações: VPP= valor preditivo positivo; VPN = valor preditivo negativo; IC 95\%=Intervalo com $95 \%$ de confiança.Critérios de positividade dos testes: Citologia convencional e Citologia em base líquida: $\geq$ ASCUS; D N A do H PV: positivo para vírus com alto risco oncogênico. 